Mesa 3

\title{
Introducción: Arte, Publicidad y Vida Cotidiana en el Espacio de Consumo
}

\author{
Antonio $\mathrm{CARO}^{1}$ \\ Universidad Complutense de Madrid
}

En la tercera sesión de nuestras Jornadas, vamos a tratar de un tema realmente polémico: las relaciones entre arte, publicidad y consumo.

Comenzando por los dos últimos, la relación entre publicidad y consumo es tan indiscutible como obvia: la publicidad ha sido desde siempre, y continúa siendo en la actualidad, el instrumento por antonomasia que incentiva el consumo e incluso el revulsivo que instala en el centro de nuestro vivir social una propensión al consumo que trata de capitalizar toda clase de energías sociales a favor de un consumismo o incluso hiperconsumismo exacerbados, en detrimento de otras actividades tenidas en principio como más «nobles».

Ahora bien, es precisamente esta realidad indiscutible lo que hace problemáticas las relaciones entre publicidad y el tercero de los ingredientes que concurren en esta mesa y en las presentes jornadas en general: el arte. Porque, si partimos de una idea «excelsa» o simplemente «noble» del arte, es evidente que una publicidad que trata de centralizar la existencia de los ciudadanos en un consumo prosaico e incluso obsceno en su idiosincrásico materialismo está reñida por definición con un arte adornado por el aura del que hablaba Walter Benjamin -permítanme pronunciar su apellido en función de su procedencia hispana y más concretamente sefardí- y cuyo destino es introducir una nota de trascendencia espiritual o de simple exquisitez en sus fruidores. Y así, el materialismo del consumo que promueve la publicidad resulta en principio incompatible con la espiritualidad que impregna al arte.

Para demostrarlo, ahí están los berrinches de muchos sacerdotes y custodios del gran arte cada vez que la publicidad utiliza para sus propios fines uno de los iconos del arte universal: ya sea la socorrida Gioconda o las no menos socorridas Tres

1 Profesor Titular de la Universidad Complutense de Madrid, actualmente jubilado. Profesor visitante de varias universidades españolas y latinoamericanas. Fundador de Pensar la Publicidad y codirector entre 2007 y 2011. Correo electrónico: antoniocaro22@gmail.com 
Gracias, cuando no las mismísimas pirámides de Gizeh o sus réplicas mayas o aztecas ubicadas al otro lado del Atlántico; préstamos que resultan con frecuencia ciertamente groseros si el creativo publicitario no los tiñe de una nota de ironía o bien traza con sutileza la afinidad implícita existente entre obra artística y objeto de consumo, a su vez espiritualizado por su marca.

Pero esta última constatación ya nos pone sobre aviso de que la cuestión no es tan simple como la plantean por lo general los popes del arte: ni los productos de consumo que anuncia la publicidad son tan groseros como lo quieren los sacerdotes del arte excelso puesto que están espiritualizados, o si se prefiere imaginarizados, por su marca, ni el gran arte está tan escindido, como parece, de la publicidad, desde el momento que éste ha tenido desde siempre un componente publicitario o, si se prefiere, propagandístico.

Son estas dos constataciones las que comienzan a poner de relieve lo complejo de la cuestión que vamos a tratar en esta mesa. En primer lugar, el objeto de consumo se ha ido dotando, como digo, de un componente espiritual en la medida que sobre el objeto específico campea una entidad claramente inmaterial, la marca, que, además de realizar el prodigio de distinguir entre sí productos idénticos, espiritualiza los bienes de consumo dotándolos de una cualidad inefable que hace, entre otras cosas, que el consumo específico de los productos necesarios para nuestra subsistencia material venga a ser un sucedáneo de esa comunión con la marca que alcanza su máxima y genuina expresión en su mostración publicitaria. (De modo que, como he señalado alguna vez, a la marca es posible adherirse, pero nunca podremos razonar por qué prestamos nuestra adhesión a una marca en lugar de otra. Y de ahí también el componente crecientemente emocional que tiene la actual publicidad en detrimento del racional, como los profesionales reconocen prácticamente de manera unánime.) Pues bien, si esto es así, ya no es tan extraño que la marca proclame con frecuencia su naturaleza espiritual convirtiéndose ella misma en icono artístico (ahí está, sin ir más lejos, la operación de marketing -especialmente visible en el caso de Chanel $^{2}$ - mediante la cual la cosmética francesa se ha dotado de un aura, construido sobre la estela artística de la alta costura parisina) o bien que una determinada marca connote su espiritualidad o su componente imaginario que la aproxima al arte stricto sensu proponiéndose como objeto de tratamiento artístico: tal como hizo en 1982 la marca Absolut por el procedimiento fuertemente publicitario de encargar a Andy Warhol, como primero de una serie de artistas

2 Así, la fundadora de la firma, la mítica Coco Chanel, era considerada por la revista Times en 1998 «entre los veinte artistas y entertainers que han marcado el siglo». RoUX, E. (2003): «Tiempo de lujo, tiempo de marcas», en LIPOVETSKY, G. Y RouX, E., El lujo eterno. De la era de lo sagrado al tiempo de las marcas, Barcelona, Anagrama, 2004, 184. 
reconocidos, la interpretación en forma de ilustración de su famosa botella ${ }^{3}$. Elevando por consiguiente la marca a la categoría de obra artística y diluyendo de este modo las fronteras aparentemente infranqueables entre publicidad y arte. Fronteras que, por lo demás, han sido desde siempre más permeables de lo que se piensa a primera vista si recordamos que un artista indiscutible como Toulouse-Lautrec debe en gran medida su fama al hecho de haberse rebajado a crear carteles para lugares tan carnales y poco espirituales como el cabaret Moulin Rouge; mientras por lo demás resulta evidente que las ilustraciones publicitarias de un Mucha, de un Cassandre, de un Ramón Casas responden sin discusión a la categoría de obras artísticas.

En cuanto a la segunda constatación citada, las evidencias son todavía más incontestables. Desde siempre, y como mínimo hasta la llegada de las vanguardias ya en el siglo XX, el gran arte ha cumplido una función propagandística que lo emparenta, de manera obvia, con la actual publicidad. Y si este componente constituía el meollo de las obras que hoy consideramos artísticas al menos hasta el Renacimiento - de manera que en el orden institucional prerrenacentista una obra era proclamada «artística» en la medida que proclamaba aquellas ideas al servicio de cuya propagación era concebida, al tiempo que las sacralizaba dotándolas de obviedad icónica-, dicho cometido se mantuvo de manera más o menos explícita en los siglos posteriores vía pintores de corte y colecciones reales que, como se sabe, fueron los orígenes de los actuales museos. De modo que cuando un determinado artista recibía el encargo de retratar a un determinado personaje, en realidad la misión que se le asignaba era propagar y preservar su imagen, y por tanto su presencia, hasta el final de los tiempos; de modo no muy distinto a como los faraones egipcios exhibían su efigie idealizada en las fachadas de los templos. Y había que tener el genio de un Goya para reducir el encargo a desnudamiento de los personajes «retratados», tal como se pone de relieve en esa maravilla artística mil veces glosada que es La familia de Carlos IV.

Pero si las dos constataciones que acabamos de ver trazan una relación mucho más íntima de lo que parece entre arte y publicidad, existe un tercer componente, tal vez menos explícito, que emparenta de manera idiosincrásica el arte -toda forma de arte- con el tercer ingrediente de nuestra mesa: el consumo. Me refiero a la fruición consumidora que acompaña a la adquisición, posesión y exhibición de

3 Una selección de tales ilustraciones se recoge en LEWIS, R. W. (1996): Absolut Book. The Absolut Vodka Advertising History, Boston y Tokio, Journey Editions, 64-85. Según el autor, fue Walhol quien propuso al Presidente/CEO de Absolut, Michel Roux, realizar la ilustración... a cambio de lo cual recibió la sustanciosa cantidad de 65.000 dólares (ibídem, $65)$. 
cualquier obra artística y que se ha ido acentuando conforme del arte como institución hemos ido pasando progresivamente al mercado del arte.

En este sentido, resulta evidente que la obra de arte -su posesión, su adquisición, su disfrute- constituye uno de los más preciados objetos de consumo. Como es bien sabido, uno de los procedimientos más utilizados para ennoblecer a un «nuevo rico» ha sido llenar su mansión de objetos sacralizados bajo el atributo de artísticos, como el genio de Orson Wells elevó hasta el paroxismo en su Ciudadano Kane. (Aglomeración de obras de arte que ha sido en ocasiones origen de prestigiosos museos, como nos recordaba el pasado domingo el suplemento semanal de El País con referencia a la Frick Collection de Nueva York, considerada uno de los mejores museos de la ciudad ${ }^{4}$.) Comprar, poseer, contemplar una obra de arte propia es otro modo de privar de esa posesión y ese disfrute a los demás, exhibirlo por consiguiente como una exclusividad que ensalza la imagen de su dueño, además de proyectar una exquisitez que la hace preferible a muchos otros objetos de consumo posibles. Y esta consideración de la obra artística como objeto de consumo que nos ennoblece ha ido cobrando intensidad conforme el mercado del arte sustituía a la vieja función propagandística que cumplía el arte tradicional al servicio de la institución que lo financiaba, proporcionando así una serialidad autorreferencial a la obra de arte contemporánea -una escultura de Botero es lo más parecido que existe a otra escultura de Botero- que Andy Warhol entendió probablemente antes que nadie. Y aproximando así cada vez más, conforme el gran arte se desacraliza, la producción y el consumo de la obra artística a los de cualquier otro producto de venta en el mercado.

\section{Referencias bibliográficas:}

LEWIS, R. W. (1996): Absolut Book. The Absolut Vodka Advertising History, Boston y Tokio, Journey Editions.

LIPOVETSKY, G. Y RouX, E. (2003), El lujo eterno. De la era de lo sagrado al tiempo de las marcas, Barcelona, Anagrama, 2004.

Rivero De LA Cruz, M. (2010): «Por amor al arte y al dinero», El País Semanal, Madrid, 14 de noviembre, 24-30.

4 Rivero de La Cruz, M. (2010): «Por amor al arte y al dinero», El País Semanal, Madrid, 14 de noviembre, 24-30. 